\title{
Online Search Behavior in the Air Travel Market: Reconsidering the Consideration Set and Customer Journey Concepts
}

\author{
Julia Andrea Jacobs, Stefan Klein \\ University of Münster \\ [firstname.lastname]@uni-muenster.de
}

\author{
Christopher Patrick Holland \\ University of Manchester \\ chris.holland@mbs.ac.uk
}

\author{
Maximilian Benning \\ University of Münster \\ mbenn07@uni-muenster.de
}

\begin{abstract}
The online air travel market is a complex and dynamic multi-channel environment in which consumers use a range of decision criteria to search for their best flight options. Online Travel Agents and Price Comparison Engines have transformed the search process and enhanced market transparency. These Air Travel Intermediaries (ATIs) are sophisticated decision support tools that enable online search and booking across thousands of flight options for all users, regardless of user expertise. An experiment was conducted to explore the detailed search behavior and processes of 29 individuals. A revised model of the customer journey as search funnel and a different operationalization of the consideration set is described that are more realistic representations of actual search behavior.
\end{abstract}

\section{Introduction}

The customer journey is a well-established model in marketing [2,25,31]. It typically starts with a wide array of purchasing options that is reduced through a series of choices culminating in a small set of serious options, termed the consideration set (CS). It is based on concepts and consumer research methods that originated in the 1960s [16]. In order to study online customer journeys, we used a search experiment for a specific product, scheduled flight tickets, as a case to reexamine this model. We chose the airline market because it is economically important, it is highly complex because of the number of permutations generated from search options and the bulk of the market is now transacted in the online channel.

The air travel market has distinct characteristics, which profoundly affect the customer journey. Air travel can be depicted as a global network of 3,275 airports (nodes) and approximately 60,000 routes (edges) [28]. Flights are defined by a departure and arrival airport and can be either direct connections between the two or combinations of several flight segments.
These connections can be operated by one or several airline brands, the latter operated by alliance partners or based on IATA interlining agreements [32]. If indirect connections are included, there may be several thousands of possible combinations of routes and airlines for a single flight. In order to process a query for a return flight from Frankfurt, Germany, to Honolulu, $\mathrm{HI}$, in the US, Opodo.com claims to have screened more than 1 million flight options.

Seat capacity on every flight is constrained and the airlines use dynamic pricing as part of a yield management strategy [21]. As flights are offered globally, available options and prices can change continuously. Therefore, decision support tools are needed in order to make this complex option space not only manageable for ordinary consumers [21], but also to give them the assurance to have identified the best flight option to suit their needs and preferences.

Three main types of competitors operate in this market: the airlines, and two types of Air Travel Intermediaries (ATI), which are Online Travel Agencies (OTAs), e.g. Expedia, Travelocity and Orbitz, and Price Comparison Sites (PCS), e.g. Kayak and Google Flight, which also support search and comparison but provide online referrals rather than booking functionality. All three use powerful algorithms to provide consumer decision support in terms of filtering flight options based on from, to, date, availability and price. The results, depicted as a matrix or list, can be further refined by relaxing search criteria, e.g. flexible dates and adjacent airports or constraining the options to specific airline brands, time of day, direct flights only and maximum price. OTAs and PCSs offer a direct comparison across a wide range or even a comprehensive set of airlines, whereas the airlines only list flight connections offered by them, which includes code sharing and interlining with other airlines to provide a connection. Global Distribution Systems (GDSs) link the airlines' reservation systems and provide the backbone for travel intermediaries to access real time information about routes, schedules, availability, and fares and to automate reservations with the airlines. GDSs therefore enable ATIs to provide market trans- 
parency [4, 32] and an easy and efficient way for consumers to compare airline brands, product characteristics and other search criteria related to the flight options available $[8,10,15,19]$. Consequently, ATIs have established a dominant position in the online travel market [34]. While the airlines initially supported ATIs as distribution partners, they have more recently increased the level of competitive manoeuvers, such as enforcing the use of airline specific booking software or introducing booking fees for intermediaries [14]. Therefore, our first research question is: Which websites do consumers use for travel search, given the online multi-channel distribution environment?

As air travel is an experience good, airlines are trying to establish their brands based on the quality of the customer experience throughout the entire service process: from booking until the luggage is delivered. Key features are flight schedule and connections, punctuality, safety, quality and amenities of the aircraft, in-flight catering and entertainment [1]. However, brand preference and for that matter brand competition only matter when customers actually have a choice among available flights offered by different airlines. Whether this is the case, can only be established based on the specific customer query and the dynamically generated list of options available at the time of the query. Although there may be an enormous number of theoretically possible flight options, these are filtered to a much smaller set of options, which actually meet the customers' baseline search criteria in terms of route and availability, which then can be further refined by adding additional search criteria.

Air travel is a service, for which search and booking occur in the "pre-consumption" phase [11,32,33]. Multiple characteristics of this service, such as origin, destination, date and time of flight, preferred carrier, class of travel, total journey time, seat and luggage options all make the search and booking process a complex and time consuming activity $[19,21]$, in particular if they are carried out online by the consumers themselves [22]. This leads us to the second research question: How do consumers search online, given the specifics of the market and the product characteristics?

The Consideration Set (CS) concept is an important link with earlier research in a pre-Internet era and also with studies that focused on online search behavior. The CS has generally been measured by counting the number of brands that the consumer actively evaluates in their search process. In this research, the CS is reconsidered in an ATI-enabled online environment. It is our contention that the use of online intermediaries fundamentally changes the online search process to such an extent that we need to model this behavior in a more realistic and specific manner.
Previous research has investigated search breadth and depth $[20,30]$ including work specifically in the airline travel market [15,18,35]. For example, Johnson et al. [18] found relatively low search levels and noted a distinctive power-law decay that describes the distribution of the number of websites visited during the search process. That is, a large number of users visit 2 or 3 websites, and this decays quickly so that only a small percentage visit 4 or more websites. More recent research into the customer journey has used online panel data to explore the search behavior of large groups of individual consumers $[15,18,35]$. Whilst this approach is very powerful at giving a broad overview, it is not possible to uncover the detailed search behavior on the travel websites in terms of search paths and multi-criteria search queries [8], at least not with standard online panel data reports. But this is a crucial part of the search process, because it is where consumers make their decisions and filter the very wide range of options down to a much smaller CS that is then evaluated to make more detailed head to head comparisons $[10,29]$. We address this gap in the literature by taking an experimental approach, where we are able to investigate the search process within the airline websites and also within the ATIs, so that we are able to develop a more sophisticated and realistic measure of search behavior and also to measure the CS by tracking individual behavior within the ATI.

Öörni [26] conducted an experiment for airline ticket search behavior and found that participants considered large numbers of alternatives and conducted several search refinements on intermediaries. Our aim is to do a modified replication of Öörni's [26] study, and to investigate flight ticket search in a more advanced and complex market. The purpose of this study is to adapt and extend the traditional customer journey model and measurement of CSs in the airline market. An experimental approach allows us to uncover important details of the search process within websites that have previously been represented as 'black boxes' within a search sequence. The detailed behavior is important because an ATI may actually constitute the whole of the online customer journey, and even a single airline website may contain several brands if it is part of a group or alliance of airlines. This internal search is therefore more representative and realistic of the search process and gives us a more nuanced method for measuring CSs. Hence our third research question is: How large is the number of actually considered flight options and airline brands (consideration set size) and how is it determined?

The structure of the paper is as follows. A review of the literature on the online search process is followed by a description and explanation of our methodology. The results from the experiment are presented, 
followed by a discussion of the results and conclusions, including the research contributions, limitations and an outline of future research opportunities.

\section{Literature review}

The literature review introduces brand categorization as a relevant marketing concept and air travel specific literature on search and consumer decision support.

\subsection{Stages of the online search process}

Search behavior is an important stage in the customer journey [22]. The consumer runs through the process of evaluating available choices, which is termed brand categorization [2,25,31]. This traditional model composes a linear process with different search stages that are distinct from each another. Consumers are not able to be aware of, nor to evaluate all the brands available on the market, therefore need to classify relevant options, so that a funneling process takes place and certain subsets are identified [5]. Shocker et al. [31] developed a theoretical framework for search behavior, focusing on the funnel process, where the set size is reduced in stages (see figure 1).

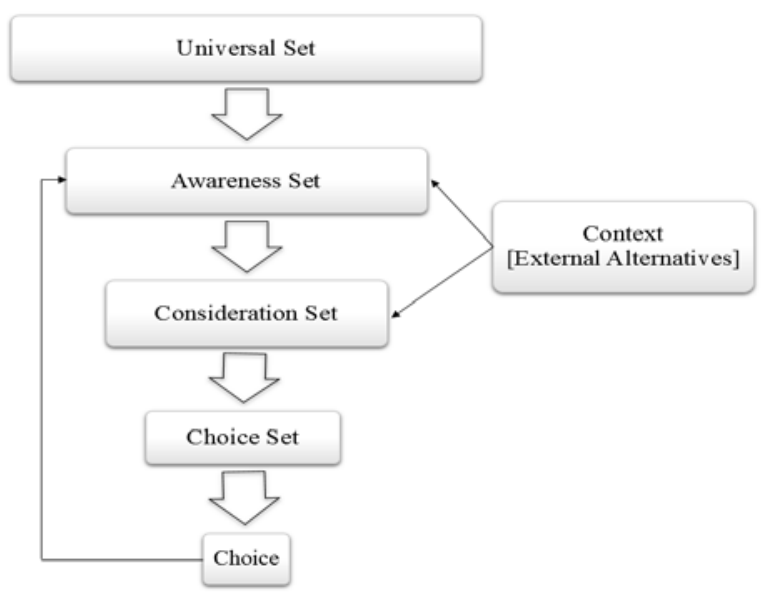

Figure 1. Brand categorisation model [31, p. 184]

In practice, it is very difficult to discern the very nuanced difference between CS and choice set, and in this paper we use the term CS for the sum of those brands that are actively considered in the search process, and from which the choice of flight is made. All possible flight options constitute the universal set. An individual consumer will only be aware of a sub-set of the universal set, which is termed the awareness set [31]. In the traditional model, the consumer's (preexisting) awareness set plays a crucial role in determining whether or not a particular competitor is considered at all. That is, if the consumer is unaware of the competitor, or does not come across them in their search, then the competitor is excluded from the search process. But in an online environment, ATIs are a powerful aid to the search process and can generate a vast range of possible options, dependent on some simple initial search criteria and not the pre-existing knowledge of the consumer. ATIs therefore change the nature and scope of the initial stages of the search process by opening up the search process to almost all airlines and flight permutations and provide a sophisticated method for filtering out and evaluating this very large possible set of options down to a manageable quantity. The awareness set concept is therefore arguably replaced by the results of the baseline query on an air travel site. After consumers enter the baseline search criteria of origin, destination and time, the ATIs and airline websites generate an initial solution space that contains the available options, which satisfy the baseline search criteria. The solution space is the result of algorithmic filtering by one or more websites, and therefore varies depending on the site(s) used. Specifically, if an airline Web site is used, the resulting solution space only represents matching flights offered by this airline and its partners. The term space is used to denote the idea of flexibility and ongoing refinement during the search process. In addition, "space” illustrates the inclusion of further flight options and airports e.g. in addition to previously included airline brands only. The evaluation of the alternatives is an iterative process of reviewing options, adjusting the filter criteria, and sorting the results list, e.g. by price or flight duration.

The next subset is the consideration set [13, p.393] 'the theoretical construct of a consideration set is those brands that the consumer considers seriously when making a purchase and/or consumption decision', also formerly known and introduced as the evoked set [16]. Shocker et al. [31, p.183] continue with a choice set to go deeper into set diminishment, explaining it as a 'final consideration set', however, this differentiation is not important for our purposes.

The consumer will eventually choose a flight from a CS based on a specific set of search criteria that have evolved over time. The CS is defined as the number of brands contained within the set of flight options that are actively viewed and considered by the consumer. The flight choice is taken from the CS in the last refinement iteration of the search process. It has been shown that ATIs reduce the CS size compared to participants not using search tools [12,29]. The number of visits to airline websites, i.e. brands, is therefore not a reliable metric. Parra and Ruiz [29] challenged the traditional concept of the CS and proposed a change 
that takes into account the nature of the online search process.

\subsection{Search behavior and decision support across intermediaries and airline websites}

Flight product characteristics, e.g. long- and shorthaul flights, and search criteria such as origin, destination, date and time of flight, preferred carrier, class of travel, total journey time, seat and luggage options all make the search and booking process a complex and time consuming activity [19]. Due to the complexity of the airline market [21], customers face an information intensive process where they need to make extensive decisions [27]. Customer decision support tools have developed and improved very quickly to such an extent that they have transformed the search experience $[6,8]$ and now significantly shape the airline ticket search process $[21,34]$. They substitute the role of the preInternet role of a travel agent $[27,32]$. With easy website designs [21], ATIs simplify and reduce the search load $[10,12,29]$. It is now the consumer who can reduce the number of available flight options by defining search criteria in an ATI. The power of the decisionmaking has therefore shifted to the individual [24,27]. Based on prior research, we think that ATIs will be increasingly used to structure the initial stages of the search process. Clemons et al. [8] describe those online intermediaries as major interaction points for a consumer for online flight ticket search. Holland et al [15] demonstrated that there is a clear interaction between ATIs and direct search, and that the use of an ATI stimulates direct search. They also found that approximately two thirds of consumers used an ATI, either on its own, or in combination with direct search. Value conscious customers may visit multiple ATIs because there continues to be price variance across online intermediaries $[6,7,8,21]$.

Our expectation is that consumers will use an ATI to shape their solution space and also to refine it. Direct search with airlines will only be used to gain very detailed information about a particular flight(s), i.e. as a further refinement of the ATI search results. For example, this could be to gain information about seating arrangements, stopover times, frequent-flyer programs, to confirm brands and to add specific in-flight or airport services [6].

\subsection{Flight ticket search criteria}

The search process model shown in table 3 captures the complexity and characteristics of the search process, in which the consumer defines the brand categorization process, or customer journey, through an iteration of entering search criteria, evaluating results and then refining the search criteria until a CS is reached and a choice is made.

The air travel Web sites follow a dominant design, which requires that all flight searches start with a baseline search of origin, destination and date. The solution space is then algorithmically generated. The search can then be further refined using additional criteria, $[8,10,19]$, thereby shaping the solution space through iterative refinements and in the detailed evaluation of flight options and brands. We argue that an important outcome of extensive use of ATIs is that the algorithmic generation of the solution space is reducing the influence of prior knowledge such as an awareness set, in the early part of the search process. If consumers do not use ATIs, then the traditional brand categorization models and customer journey models are much more appropriate because they take into account the importance of the awareness set in the search process.

\section{Methodology}

An experimental approach was chosen in order to be able to explore, document and evaluate the search process in a controlled environment [12,17,29]. Microsoft Expression was used to video the computer screens of the participants. In this way, we were able to compare search efforts, measure search sequences and patterns, and ask the search subjects to explain their search strategies. This enables the researcher to gain a good approximation of real consumer behavior in a realistic setting. The experiment is a modified replication of Öörni's [26] experiment to make it comparable and to rely on a proven method to investigate online search behavior [29].

\subsection{Experiment}

A within-group laboratory experiment was conducted with 29 undergraduate students enrolled in an ecommerce course at a German university. The male: female ration was 76:24 and the age range was 20 to 28 years. The experiment was organized as an integral part of the course program but participation was voluntary and no credits were awarded. Participants were asked to search online for a suitable one-way, longhaul flight from Frankfurt (FRA) to Honolulu (HNL) with a desktop computer. They were instructed to find the best option without any further specification. They were free to use any website they liked. Their search behavior was documented by a video recording of their computer screens. Before they started their search task, participants used an ID to anonymize the recording and the researchers certified the anonymous use of data. After the task the students were asked to fill out an 
online questionnaire. Students were able to break off the participation at any time. 29 videos were recorded of which 24 were used for the analysis. Five of the recordings were incomplete and unusable. Students were given 30 minutes to complete their tasks and this was enough time for all participants to finish the assignment.

We chose to design the experiment as a modified replication of Öörni's [26] study to focus on product characteristics and search criteria influencing the search pattern for online air travel behavior. Compared to Öörni's [26] study, the number of participants was lower (29 compared to 92 students in the original study). Although students were not awarded any course credit for their participation, they were given a symbolic token of appreciation, sweets, for their participation. Hawaii was used again as a destination and search criteria in terms of CS size were measured. Furthermore, we have focused on online search only and the search patterns, specifically which websites are used to conduct their searches and which search criteria are important regarding which search scenario. Öörni [26] focused on the evaluation of the results based on a comparison of traditional versus electronic markets and did not explore the consumer search process in detail. In our experiment we focused exclusively on the nature of the search process, the search sequence as well as search criteria used by the participants.

The videos were analyzed and participants' search activities were coded into a spreadsheet. More precisely, the search patterns (start and end point), the search sequence and their final booking page were tracked and their importance related to search criteria. The number of flight options and the CS were measured. If a searcher used more than one ATI, then the results were combined to establish the number of brands in the CS. This approach is consistent with the technical definition of a CS [3]. If a flight option is code shared between different brands, only the first airline was accounted as a brand. Finally, the participants were asked to rank their three most important search criteria related to the flight option chosen.

\subsection{Customer journey and brand categoriza- tion}

The extensive use of ATIs makes it difficult to evaluate the actual CS of searchers because they are exposed to a large number of brands, presented in some form of comparison list [34]. Whenever decisions support tools (ATIs) are used, the identity and overall number of considered brands becomes a black box to researchers using online panel data. However, with our experiment we aimed to open this black box and investigate the search process in sufficient detail to be able to count the number of brands that are considered when consumers use ATIs. The search scenario assigned to the participants in the experiment defines the baseline criteria, which yields the initial solution space. This initial solution space can be refined during several iterations by the participant into a refined set of flight alternatives. Flight options are the sum of search results displayed on all websites visited by a participant. Flight options are analyzed for the funnel process, however, they are not relevant in determining the CS size.

In the context of online air travel, the term CS becomes potentially ambiguous. One must first distinguish between flight options and then brands. One airline brand might offer several flight options and we argue that to maintain consistency with earlier research, then the number of brands is the key measure. However, should the number of brands in the solution space be counted? Or is it more realistic to analyze the number of brands that are actively considered? The latter approach is taken but even here one must interpret the meaning of the term active in an online search context where customers are scrolling through pages of search results. We have measured the CS by counting the number of airline brands visible on the Web pages displaying the final sets, including scrolling and mouse movements and are thus regarded as actively considered within the ATI and the airline Web sites, in case they have been used as well. This metric is consistent with the theoretical definition of a CS [3] but is arguably a broader measure than previous measurements that used online panel data and only counted a brand if the user visited the actual website [15, 18, 35]. There are two differences that have to be kept in mind: (1) codesharing flight options are only counted once and assigned to the main brand; (2) some flights, especially long-haul flights are offered jointly by different airlines in order to be able to cover the route. In that case, only the main brand is counted.

\section{Findings and Analysis}

The presentation of findings follows the sequence of our research questions.

\subsection{Choice of Web Sites for the Search}

Search for available flights can be conducted in two ways: direct search on airline websites or by using online intermediaries, i.e. ATIs, which can be used separately or in combination. The results of online search patterns are shown in table 1.

Participants preferred ATI for their search and often combined different comparison websites during 
their search session. Some of the participants started their search on a general search engine rather than looking for a travel site. The search engine listed links to flight comparison sites and a few airlines, which prompted the user to continue their search. They then continued with an ATI or airline website. Some users then used ATIs only or combined it with an airline website during their search sequence and finished either on an ATI or airline website. The majority of the participants (92\%) started their search on ATIs and continued on them only without considering an airline website (71\%). 88\% of the participants terminated their search on an ATI. Airline websites were less frequented: only four concluded their search on an airline website but did not book on the latter. While seven participants (29\%) visited airline websites at some stage during their search, none of the participants searched on airline sites only. These findings are contrary to Holland et al. [15], who reported that a third of German consumers searched only on airline websites. However, one needs to take into account the difference between an experimental survey and an online panel used by Holland et al. [15].

Table 1. Airline search pattern on decision support tools and brand websites

\begin{tabular}{|l|l|r|r|}
\hline \multirow{2}{*}{ Search pattern } & \multicolumn{1}{|c|}{ Website } & $\begin{array}{c}\text { \# of par- } \\
\text { ticipants }\end{array}$ & \multicolumn{2}{c|}{$\%$} \\
\hline \multirow{2}{*}{ Start search on ... } & ATI & 22 & 92 \\
\cline { 2 - 4 } & Airline & 2 & 8 \\
\hline \multirow{2}{*}{ Searching on ... } & ATI only & 17 & 71 \\
\cline { 2 - 4 } & ATI and Airline & 7 & 29 \\
\hline \multirow{2}{*}{$\begin{array}{l}\text { Start website : end } \\
\text { website }\end{array}$} & ATI : Airline & 1 & 4 \\
\cline { 2 - 4 } & ATI : ATI & 21 & 88 \\
\cline { 2 - 4 } & Airline : ATI & 2 & 8 \\
\hline \hline Total & & 24 & 100 \\
\hline
\end{tabular}

\subsection{Flight ticket search behavior}

Participants showed an ongoing refinement process of the search task by either modifying criteria (e.g. different airport, other dates) or further constraining criteria (e.g. earlier arrival time). Hence, their search was a mixture of browsing or screening the results page, refining and adding search criteria.

The search task defined baseline criteria: route (FRA - HNL), travel period in terms of departure and arrival time. Further search criteria were at the discretion of the participants. In the post-experiment survey, participants ranked their three most important search criteria (table 2). The most important criteria are the ticket price, closely followed by the flight duration and the number of connections or stopovers. This confirms Collins et al.'s [10] results. Flight departure and arrival time, the attractiveness of the transit airports as well as airline brand and the layover were less frequently mentioned. As a second most important factor, the top three ranks are price, the number of connections and the transit airport.

Table 2. Flight selection criteria

\begin{tabular}{|l|r|r|r|}
\hline Selection criteria & $\begin{array}{l}\text { Most im- } \\
\text { portant cri- } \\
\text { teria (\%) }\end{array}$ & $\begin{array}{l}\text { 2 } \\
\text { important } \\
(\%)\end{array}$ & $3^{\text {rd }}$ (\%) \\
\hline Price & 52 & 26 & 20 \\
\hline Flight duration & 18 & 16 & 40 \\
\hline Number of stops & 9 & 26 & 40 \\
\hline $\begin{array}{l}\text { Departure/ arrival } \\
\text { time }\end{array}$ & 6 & 6 & $\mathrm{n} / \mathrm{a}$ \\
\hline $\begin{array}{l}\text { Transit airports } \\
\text { (stopover) }\end{array}$ & 6 & 21 & $\mathrm{n} / \mathrm{a}$ \\
\hline Airline brand & 6 & 5 & $\mathrm{n} / \mathrm{a}$ \\
\hline Layover & 3 & $\mathrm{n} / \mathrm{a}$ & $\mathrm{n} / \mathrm{a}$ \\
\hline $\mathrm{N}$ & 33 & 19 & 5 \\
\hline
\end{tabular}

The combination of criteria suggests that travelers have to make complex trade-offs, such as: how much more am I willing to pay for a more convenient flight in terms of overall travel time or times of departure and arrival; or how much more am I willing to pay for a different airline operating my flight?

The number of participants mentioning criteria decreases with the ranking as it was not mandatory to select three options. As we chose students as participants, we obviously have selected a price-sensitive customer segment. However, the high ranking of price as selection criterion for flights is representative for a large customer segment [1]. The baseline criteria have been chosen to simulate a complex flight choice: direct flights are not available for the route FRA - HNL, travelers have the choice of taking the eastern route (via Asia) or the Western route (via North America).

\subsection{Flight options and airlines considered}

The experiment design allowed us to capture the refinement of selection criteria and at the same time to document the size of the initial and refined solution spaces as well as the CSs. Table 3 shows search figures of flight options at different stages of the funnel.

Some participants started their search on search engines, with origin and destination details only and no time restrictions (not necessarily needed), giving a high 'origin - destination solution space' of 8,777 flight alternatives. This number represents the total number of flight options for the route Frankfurt to Honolulu. The search engine had assumed a random date (Feb. 13) and counted code-shared flights as well as flight sold via tour operators as distinct options.

By entering all the baseline criteria with time restrictions, an average number of 368 flight options are 
available in total in the 'origin, destination, time solution space'. All participants conducted several (at least 3) refinement iterations. The refinement stages were either conducted on the chosen intermediary website or other websites were selected for comparison. The flight options during the refinement process were counted at every iteration step. They have been decreasing from 326 to 76 flight options on average. Finally, the participants considered on average 23 flight alternatives during the search process and considered 11 airline brands.

Table 3. Flight ticket search funnel

\begin{tabular}{|c|c|c|}
\hline $\begin{array}{l}\text { Adapted } \\
\text { brand cat- } \\
\text { egorization }\end{array}$ & $\begin{array}{l}\text { Metrics and com- } \\
\text { ments }\end{array}$ & $\begin{array}{l}\text { Experimental } \\
\text { results [FRA - } \\
\text { HNL] }\end{array}$ \\
\hline $\begin{array}{l}\text { Universal } \\
\text { set }\end{array}$ & b) All airline brands & $\begin{array}{l}\text { a) Appr. 60,000 } \\
\text { routes, millions } \\
\text { of combinations } \\
\text { of routes } \\
\text { b) Appr. 6,000 } \\
\text { airlines [28] }\end{array}$ \\
\hline $\begin{array}{l}\text { Initial } \\
\text { solution } \\
\text { space }\end{array}$ & $\begin{array}{l}\text { a) Origin, destina- } \\
\text { tion, default time } \\
\text { (set by site) } \\
\text { b) Origin, destina- } \\
\text { tion, time }\end{array}$ & $\begin{array}{l}\text { a) 8,777 flight } \\
\text { options } \\
\text { b) Avg. } 368 \text { flight } \\
\text { options }\end{array}$ \\
\hline $\begin{array}{l}\text { Refined } \\
\text { solution } \\
\text { space } \\
\end{array}$ & $\begin{array}{l}\text { Stepwise refinement } \\
\text { of search criteria }\end{array}$ & $\begin{array}{l}\text { Avg. } 326-76 \\
\text { flight options }\end{array}$ \\
\hline $\begin{array}{l}\text { Considera- } \\
\text { tion set }\end{array}$ & $\begin{array}{l}\text { a) Flight alternatives } \\
\text { considered } \\
\text { b) Airline brands } \\
\text { considered }\end{array}$ & $\begin{array}{l}\text { a) Avg. } 23 \text { flight } \\
\text { options } \\
\text { b) Avg. } 11 \text { brands }\end{array}$ \\
\hline
\end{tabular}

An example of average number of flight alternatives of the participants at each search stage is given and demonstrates the intensity of the filtering process, reducing the available flight options from a total of 8,777 to an average of 23 flight options for the consumer. In order to measure the search breadth for flight tickets, available flight options and CS size were observed for each participant. The following table 4 gives an overview.

A total number of 24 different airline brands were operating (segments of) the flight route from Frankfurt to Honolulu and could have been chosen by the participants. For each participant, ranked by ID, the total number of flight options considered as well as his or her CS size were calculated based on the video capture of their scrolling and mouse behavior. The number of flight options are calculated based on the number of flight options displayed on various ATIs and airline websites considered by each participant. The total range of all the flight options considered is 8-46. On average, participants considered 22.5 flight options with a standard deviation of 9.75. Out of these flight options, all airline brands considered are forming the CS size with a total range of 5-15 brands. On average, participants considered 11 airline brands with a standard deviation of 2.97.

Table 4. Consideration set (CS) size and number of flight options

\begin{tabular}{|c|c|c|c|c|c|}
\hline \multicolumn{6}{|c|}{ All available brands $(\mathrm{N}=24)$} \\
\hline \multicolumn{6}{|c|}{$\begin{array}{l}\text { Aer Lingus, Aeroflot, Air Berlin, Air Canada, Air China, } \\
\text { Air France, American Airlines, Asiana Airlines, British } \\
\text { Airways, Cathay Pacific, China Eastern Airlines, Condor, } \\
\text { Delta Air Lines, Ethiopian Airlines, Iberia, Icelandair, } \\
\text { Japan Airlines, KLM, Korean Air, Lufthansa, SAS, } \\
\text { Swiss, Thomas Cook, United Airlines }\end{array}$} \\
\hline ID & $\begin{array}{l}\text { Number } \\
\text { of flight } \\
\text { options }\end{array}$ & $\begin{array}{l}\text { CS } \\
\text { size }\end{array}$ & ID & $\begin{array}{l}\text { Number } \\
\text { of flight } \\
\text { options }\end{array}$ & CS size \\
\hline 1 & 37 & 12 & 13 & 35 & 15 \\
\hline 2 & 27 & 12 & 14 & 18 & 9 \\
\hline 3 & 20 & 6 & 15 & 11 & 5 \\
\hline 4 & 20 & 8 & 16 & 16 & 5 \\
\hline 5 & 25 & 12 & 17 & 21 & 8 \\
\hline 6 & 29 & 7 & 18 & 38 & 12 \\
\hline 7 & 14 & 10 & 19 & 17 & 8 \\
\hline 8 & 8 & 5 & 20 & 24 & 14 \\
\hline 9 & 37 & 12 & 21 & 15 & 7 \\
\hline 10 & 10 & 5 & 22 & 16 & 7 \\
\hline 11 & 46 & 9 & 23 & 15 & 5 \\
\hline 12 & 21 & 8 & 24 & 20 & 10 \\
\hline
\end{tabular}

\section{Discussion}

Our aims for this paper were to investigate characteristics of the online search process for air travel products shaped by the complexity of the air travel market and competition in the online distribution system (1), search patterns for flight tickets in light of thousands of available flight options and algorithmic search and filtering tools operating on air travel Web sites (2) and how the theoretical concepts of customer journey and CS changed (3). While various methods have been used previously to uncover search behavior online $[9,15]$, previous findings have provided little insight into online search paths or search intensity. We therefore conducted a laboratory experiment with students in order to capture the customer journey in detail. By using an experiment, the researchers were able to open the black box of flight search behavior and demonstrate the need for theory concept development and adaptation, particularly for the sales funnel and consideration set. The airline market is different to other markets and its specificities influence the need for concept adaptation of the customer journey and CS. The nature of the search process, flight search behavior and criteria used are linked and explain the importance 
of being considered in combination to gather insights into consumer behavior.

\subsection{Channel competition}

Online ATIs have a dominant role, as they are an obvious choice to gather an overview of available flight options. Across all air travel sites, the first stages of the search process are quite similar with online forms to enter the baseline criteria. During the search process, the ATIs have a clear advantage in terms of transparency. Only if the airline (brand) has already been chosen, the airline sites are advantageous as they generate much smaller and therefore less complex option spaces. Once the choice for a flight has been made, airline websites provide the advantage of highly differentiated product choices (e.g. booking class, luggage requirements, leg space, ticket changes and cancellations fees). Lufthansa recently introduced a booking fee for OTAs, which provides a disincentive for travelers to use OTAs for the booking process [14].

The complexity of options and the variation in prices and fees provide a plausible explanation for the observed "site hopping": all participants checked alternative sites in order to see whether they would encounter different flight options or price differences.

\subsection{Algorithmic search and consumer decision support}

When a consumer starts to search for a flight, they typically have very little idea what the solution space will look like. Even when they are familiar with routes and schedules, the availability of seats and the airfare are only retrieved at the time of search. Hence, search and comparison algorithms (“engines”) determine online search and are used by all air travel sites.

Based on the baseline criteria the algorithms dynamically generate the solution space, which is a transient list, as availability of seats (in a particular booking class, i.e. price category) can change any second. Some sites even signal the number of available seats at the listed price. Depending on the characteristics of the initial solution space, the consumer can expand the search by relaxing the baseline criteria or reduce the solution space, by adding constraints, such as number of stops, time of departure, or preferred airline(s). Our results show an alternating process of screening results and refining parameters, typically three rounds of refinement. Öörni [26] found that consumers conducted several search iterations, corroborating our results.

Once the final solution space has been established, the remaining options are examined ("actively considered”), possibly sorted based on decision criteria and the participants consider tradeoffs between their deci- sion criteria. We have surveyed our participants and asked for up to three ranked decision criteria, which revealed different preference profiles. While the majority named price as the most important criterion, facets of convenience (flying time, number of stops and layover) scored highly in particular as second and third criteria. The transit airport was considered by $21 \%$ as a second criterion, which may reflect the condition of a long haul flight and the option for an extended stopover.

The online search process shows the salience of the decision support tools offered by the travel Web sites in terms of filtering, refining search and sorting results. The consumers refine the search by using a simple interface, but in the end have to make a choice themselves based on their preferences and related trade-offs. Given the transient nature of the solution space, some sites offer the consumer to literally buy time, by temporarily putting flight options on hold, in order to allow time to think, consult or substantiate a tentative choice.

\subsection{Refining brand categorization}

Based on our analysis and findings we are suggesting two amendments to the brand categorization model or search funnel:

(1) Given the prominence of online consumer decision support tools and the product characteristics of air travel we propose to replace the awareness set (an individual's representation of the brand space) by the concept of the initial solution space: algorithmically generated, currently available options meeting the consumer's baseline criteria. Brand is only included as an initial selection criterion in case the travelers start their search on an airline website. The notion of solution space includes a process view of sequential refinements until a final solution space has been identified, which more accurately reflects consumers' preferences.

(2) The final solution space comprises the total number of flight options that meet the customer's detailed choice criteria, which we propose to use as the basis for counting the number of brands in the CS of the actively considered flight options, evidenced by scrolling, mouse movements or clicking on options.

CS size and number of flight options considered are higher compared to prior studies [15,18,26,35] as a result of our methodological approach. Prior studies have operationalized the CS as the number of airline websites visited. These results are specific to the airline market and take a broader view of active consideration. 


\section{Conclusion and limitations}

Our study aimed at opening the black box of online search for scheduled air travel. Based on a thorough contextualization of the air travel market, of the competition in the online multi-channel distribution system and of the characteristics of air travel services, we have created video protocols of realistic search processes. The experiment revealed detailed search paths within and across air travel sites and confirmed the expected prevalence of ATIs in the early stages of the search process, as search algorithms and the related consumer decision support tools on ATI websites have considerably improved over the past years. The tools have become more flexible, including a higher number of possible search and filter criteria and providing higher levels of transparency by covering all flight options (including low cost airlines) and allowing for extending and constraining the solution space. While earlier work $[21,26]$ had documented the challenges for consumers to search online for complex, long-haul flights, our participants did not encounter substantial difficulties and all identified suitable flight options within a reasonably short period of time. The results also suggest that airlines should focus on the booking process and complement the ATIs, rather than compete with them head-on during the early stages of search.

The experiment also provided insights into the dynamics of search, which we have divided into three phases: (1) filtering and refining search criteria, (2) comparing and examining the CS and (3) eventually deciding based on trade-offs between preferences. It revealed the key role of the decision support tools but also their limitation when it comes to supporting the final decision. The trade-offs might be addressed by a new generation of decision support tools. The results of our experimental findings suggest a revision of the brand categorization model, specifically for online search of airline tickets and methodological enquiries, which reveal the flight options and brands considered by the consumers. The amendments relate to the replacement of awareness set by a dynamically refined solution space and a distinct operationalization of the CS based on observations of the active consideration of flight options.

Our research design has obvious limitations in terms of the number and demographics of the participants. Yet, despite the widespread concern about student participants in experiments, they represent a technologically savvy, but relative inexperienced customer segment, which is quite suitable for the purpose of our study. Laboratory experiments are not executed in a natural environment that might represent participants' natural search behavior as other social factors also influence the decision [26]. We are planning to extend the sample size and the data capture by including speak-aloud components in a future design. We will use our findings from this study as part of a larger research program, which includes a synthesis of online panel data, weblog analysis and experiments.

\section{References}

[1] S. Aksoy, E. Atilgan, and S. Akinci, “Airline services marketing by domestic and foreign firms: differences from the customers' viewpoint”, J. of Air Transport Management, 9, 2003, pp. 343-351.

[2] J. Brisoux, and M. Laroche, "A proposed consumer strategy of simplification for categorizing brands”, In: Evolving Marketing Thought for 1980, J. H. Summey and R. D. Taylor (eds.), Southern Marketing Association, Carbondale, IL. 1980, pp. 112-114.

[3] J.J. Brown, and A.R. Wildt, "Consideration set measurement”, J. of the Academy of Marketing Science, 20(3), 1992, pp. 235-243.

[4] D. Buhalis, and M.C. Licata, "The future etourism intermediaries”, Tourism Management, 23(3), 2002, pp. 207-220.

[5] B.M. Campbell, The Existence of Evoked Set and Determinants of its Magnitude in Brand Choice Behavior. Unpublished Ph.D. dissertation, Columbia University, 1969.

[6] J. Chen, "Differences in average prices on the Internet: Evidence from the online market for air travel”, Economic Inquiry, 44(4), 2006, pp. 656-670.

[7] W-C. Chiou, C-C. Lin, and C. Perng, "A strategic website evaluation of online travel agencies”, Tourism Management, 32(6), 2011, pp. 1463-1473.

[8] E.K. Clemons, I.-H. Hann, and L.M. Hitt, "Price dispersion and differentiation in online travel: An empirical investigation”, Management Science, 48(4), 2002, pp. 534-549.

[9] A.T. Collins, J.M. Rose, and S. Hess, "Search based internet surveys: airline stated choice”, Working paper ITLSWP-10-01, ITLS Sydney and ITS Leeds, 2010, pp. 1-15.

[10] A.T. Collins, J.M. Rose, and S. Hess, "Interactive stated choice surveys: a study of air travel behavior”, Transportation, 39(1), 2012, pp. 55-79.

[11] U. Gretzel, D.R. Fesenmaier, and J.T. O’Leary, “The Transformation of Consumer Behavior”, In: Tourism Business Frontier, D. Buhalis and C. Costa. (eds.), Oxford, UK, Butterworth-Heinemann, 2006, pp. 9-18.

[12] G. Häubl, and V. Trifts, "Consumer decision making in online shopping environments: The effects of interactive decision aids”, Marketing science,19(1), 2000, pp. 4-21.

[13] J.R. Hauser, and B. Wernerfelt, "An evaluation cost model of consideration sets", J. of Consumer Research, 16(4), 1990, pp. 393-408.

[14] G. Hobica, "Four Airlines to add a fee for booking with expedia, priceline, etc.”, Huffington Post Blog, 06.05.2015, accessed $29^{\text {th }}$ August 2016, 
http://www.huffingtonpost.com/george-hobica/four-airlinesto-add-a-fe_b_7518076.html.

[15] C.P. Holland, J.A. Jacobs, and S. Klein, "The role and impact of comparison websites on the consumer search process in the US and German airline markets”, J. of Information Technology and Tourism, 16(1), 2016, pp. 127-148.

[16] J.A Howard, and J.N. Sheth, The Theory of Buyer Behavior. John Wiley \& Sons, New York, 1969.

[17] J. Jacoby, R.W. Chestnut, and W.A. Fisher, “A Behavioral Process Approach to Information Acquisition in Nondurable Purchasing”, J. of Marketing Research, 15 (Nov), 1978, pp. 532-544.

[18] E.J. Johnson, W.W. Moe, P.S. Fader, S. Bellman, and G.L. Lohse, "On the depth and dynamics of online search behavior”, Management science, 50(3), 2004, pp. 299-308.

[19] S.H. Jun, C.A. Vogt, and K.J. MacKay, “Online Information Search Strategies: A Focus on Flights and Accommodations”, J. of Travel and Tourism Marketing, 27(6), 2010, pp. 579-595.

[20] L.R. Klein, and G.T. Ford, „Consumer search for information in the digital age: an empirical study of prepurchase search for automobiles”, J. of Interactive Marketing, 17(3), 2003, pp. 29-49.

[21] S. Klein, F. Köhne, and A. Öörni, "Barriers to Online Booking of Scheduled Airline Tickets", J. of Travel and Tourism Marketing, 17(2/3), 2004, pp.27-39.

[22] P. Kotler, G. Armstrong, J. Saunders, and V. Wong, Principles of marketing, $5^{\text {th }}$ European edition, London, Pearson, 2008.

[23] I. Lewis, J. Semeijn, and A. Talalayevsky, “The impact of information technology on travel agents”, Transportation Journal, 37(4),1998, pp.20-26.

[24] P. Lin, C. Chen, and M. Song, "Price dispersion of online air tickets for short distance international routes", Service Industries Journal, 29(11), 2009, pp. 1597-1613.

[25] C.L. Narayana, and R.J. Markin, “Consumer Behavior and Product Performance: An Alternative Conceptualization”, J. of Marketing, 39(4), 1975, pp. 1-6.

[26] A. Öörni, “Consumer search in electronic markets: an experimental analysis of travel services”, European Journal of Information Systems, 12, 2003, pp. 30-40.

[27] R. O’Keefe, and T. McEachern, “Web-based customer decision support systems”, Communications of the ACM, 41(3), 1998, pp. 71-78.

[28] Openflights. Airport Database. Accessed 29 ${ }^{\text {th }}$ August 2016, http://openflights.org/data.html.

[29] J.F. Parra, and S. Ruiz, "Consideration sets in online shopping environments: the effects of search tool and information load", Electronic Commerce Research and Applications, 8(5), 2009, pp. 252-262.

[30] C.M. Schaninger, and D. Sciglimpaglia, “The Influence of Cognitive Personality Traits and Demographics on Con- sumer Information Acquisition”, J. of Consumer Research, 8(2), 1981, pp.208-216.

[31] A.D. Shocker, M. Ben-Akiva, B. Boccara, and P. Nedungadi, "Consideration set influences on consumer decision-making and choice: Issues, models, and suggestions”, Marketing Letters, 2(3), 1991, pp. 181-197.

[32] H. Werthner and S. Klein, "ICT and the Changing Landscape of Global Tourism Distribution“, Electronic Markets, 9(4), 1999, pp. 256-262.

[33] H. Werthner, and S. Klein, Information, technology and tourism: A challenging relationship, Springer Computer Science, Springer, Vienna, Austria, 1999.

[34] Z. Xiang, V.P. Magnini, and D.R. Fesenmaier, "Information technology and consumer behavior in travel and tourism: insights from travel planning using the internet”, J. of Retailing and Consumer Services, (22), 2015, pp. 244-249.

[35] J. Zhang, X. Fang, and O.R. Liu Sheng, "Online consumer search depth: Theories and new findings”, J. of Management Information Systems, 23(3), 2006, pp. 71-95.

\section{Appendix: scenario description}

Please select Google as your starting homepage. Please enter your ID code into the search bar. Now read the following scenario: Please imagine the following situation: You just finished your Bachelor studies and you want to do a trip with a friend to Hawaii. You have a joint friend who's studying in Honolulu (Hawaii) and together you want to continue the trip from there. As you are not sure yet at what point you will fly back, you are only interested in a one-way flight Frankfurt (FRA) to Honolulu (HNL). You have arranged to meet your friend not later than February $14^{\text {th }} 21.00 \mathrm{~h}$ (local time). For personal reasons you cannot leave Frankfurt before Feb. $12^{\text {th }}$. Please search online for flights which you would choose under the circumstances. The choice of websites is yours. Please document your final flight choice by taking a screenshot that documents the flight no., day, time and price. Or, write your final choice on the sheets provided. Just look for the price of a simple, one-way economy ticket for one adult, i.e. without extra luggage, insurance, special seating, loyalty programs etc. You will be paying by credit card. Your friend has asked you to find and recommend the best options, so please identify your favorite list of one to three options. For each option, please continue to search up to the point where you will be asked to make a payment. (Please don't make any real booking!). You may be asked to enter your personal details (feel free to invent information e.g. Examplestreet 5, 48159 City). Please document the top 1-3 flight choices of your flight search results (flight no., time, day, price) in a word document or the table provided. Briefly explain your recommendation including your preferences, i.e. your ranking, in 2-3 sentences. (Expected time for scenario: 10-15 min). 